\title{
Erratum
}

\section{Effect of hysterectomy on incidence trends of endometrial and cervical cancer in Finland 1953-2010}

\author{
R Luoto, J Raitanen, E Pukkala and A Anttila
}

British Journal of Cancer (2004) 91, 1979. doi:I0.1038/sj.bjc.6602288 www.bjcancer.com

(c) 2004 Cancer Research UK

Correction to: British Journal of Cancer (2004) 90, 1756-1759. doi: 10.1038/sj.bjc.6601763

Due to an error, Table 1 and some text on page 1756 of the above paper were shown incorrectly. The correct Table 1 and text are given below:

Table I Number $(N)$ and incidence of total and partial hysterectomies in Finland $199 \mid-99$, and incidence of endometrial and cervical cancer with and without correction for hysterectomies

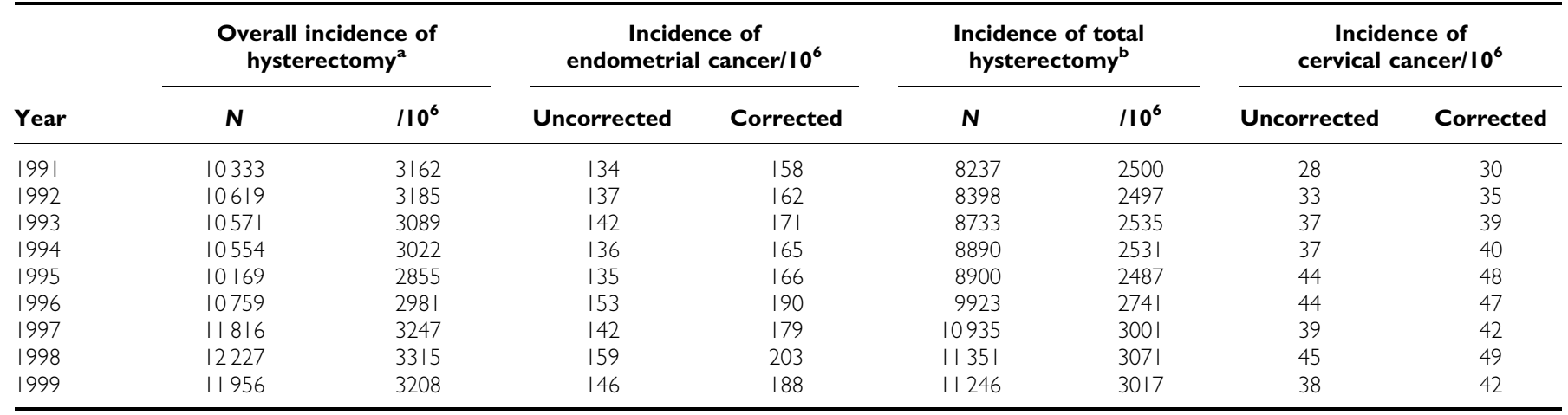

${ }^{\mathrm{a} A l l}$ incidence rates are adjusted for age to the world standard population. ${ }^{b}$ Number of women with hysterectomy, cervix removed.

On page 1756 of this article, the second sentence in the Results section should read as follows:

The incidence of hysterectomies with cervix removed increased from 2500 in 1991 to 2017 per million women in 1999. 